\title{
Toward the Operability of Flotation Systems under Uncertainty
}

\author{
Freddy A. Lucay ${ }^{1, *(D)}$, Renato Acosta-Flores ${ }^{2}$, Edelmira D. Gálvez ${ }^{3}$ and Luis A. Cisternas ${ }^{4}$ (D) \\ 1 Escuela de Ingeniería Química, Pontificia Universidad Católica de Valparaíso, Valparaíso 2340000, Chile \\ 2 Unidad de Equipamiento Científico (Maini), Universidad Católica del Norte, Antofagasta 1240000, Chile; \\ renato.acosta@ucn.cl \\ 3 Departamento de Ingeniería Metalúrgica y Minas, Universidad Católica del Norte, \\ Antofagasta 1240000, Chile; egalvez@ucn.cl \\ 4 Departamento de Ingeniería Química y Procesos de Minerales, Universidad de Antofagasta, \\ Antofagasta 1240000, Chile; luis.cisternas@uantof.cl \\ * Correspondence: freddy.lucay@pucv.cl
}

Citation: Lucay, F.A.; Acosta-Flores, R.; Gálvez, E.D.; Cisternas, L.A. Toward the Operability of Flotation Systems under Uncertainty. Minerals 2021, 11, 646. https://doi.org/ $10.3390 / \min 11060646$

Academic Editor: Lev Filippov

Received: 31 March 2021

Accepted: 15 June 2021

Published: 18 June 2021

Publisher's Note: MDPI stays neutral with regard to jurisdictional claims in published maps and institutional affiliations.

Copyright: (c) 2021 by the authors. Licensee MDPI, Basel, Switzerland. This article is an open access article distributed under the terms and conditions of the Creative Commons Attribution (CC BY) license (https:// creativecommons.org/licenses/by/ $4.0 /)$.
Abstract: The purpose of this work was to analyze the requirements for the operational feasibility of flotation systems as well as the effects of the selection of flotation equipment and metal price uncertainty. A procedure based on mathematical optimization and uncertainty analysis was implemented to achieve this aim. The optimization included flotation and grinding stages operating under uncertainty, whereas the uncertainty analysis considered the Monte Carlo method. The results obtained indicate a small number of optimal flotation structures from the economic point of view. Considering the relationship between the economic performance and metallurgical parameters, we established that these structures exhibited favorable conditions for operating under uncertainty. Such conditions were proportional to the percentages representing each structure in the optimal set; i.e., a higher percentage of a structure implied a greater capacity to face operational and metal price changes. The set of optimal structures included configurations implementing cell banks, flotation columns, or both, indicating the influence of the flotation equipment type on the optimal structures. We also established the influence of metal price on the number of optimal structures. Therefore, the results obtained allowed us to separate the design of the flotation systems into two stages: first, a set of optimal structures exhibiting favorable conditions for facing uncertainty is determined; second, the optimal operation is established via resilience/flexibility approaches after the previous determination of the equipment design parameters.

Keywords: design; flotation systems; uncertainty analysis; selection of equipment; grinding

\section{Introduction}

Historically, flotation circuits have included cell banks; however, changes in the processed ore, operational grinding conditions, technological developments, valuable metal prices, energy, and water consumption have generated an evolution from circuits to flotation systems. These systems include flotation cell banks, flotation columns, and grinding units, with an arrangement that is complex to determine as the design alternatives markedly increase as the number of processing stages increases [1].

When industrial aspects are considered, several issues arise. Flotation systems process a large number of mineralogical species, which increases the complexity of the problem. These species include particles of different sizes, shapes, and mineral compositions together with a liquid-gas medium, which makes the systems challenging to model. On the other hand, the design of these flotation systems is addressed by considering the experience of the designer and is supported by laboratory/pilot tests, simulation, and modeling. The number of design alternatives is significant, which limits the evaluation and selection of alternatives during laboratory/pilot tests. In addition, uncertainty, such as metal price and ore composition, adds complexity to the problem. Thus, the design of flotation systems considering all aspects mentioned is technically and economically non-viable. 
The available literature reports design procedures focused on concentration circuits implementing mainly cell banks. These procedures are based on mathematical programming and include the following ingredients: a superstructure of alternatives, a mathematical model, and an algorithm to solve the problem [2]. The resulting mathematical model is typically a mixed-integer non-linear programming (MINLP) problem, which is difficult to solve [3]. Several authors have proposed implementing certain assumptions to handle the design problem. For example, Cisternas et al. [4] proposed describing the recoveries in flotation stages via distribution functions, resulting in a mixed-integer linear programming (MILP) problem. They reported that there are few optimal structures for a wide range of recoveries; i.e., the recovery of mineralogical species has a minor effect on the optimal structures. Based on these results, methodologies to design flotation circuits in two steps were proposed [5-7]: first, the researchers detected a set of optimal circuit structures using distribution functions to represent the stage recoveries, and second, the optimal design was determined for each of the optimal structures. Similarly, Acosta-Flores et al. [8] proposed characterizing both the flotation stage recovery and grinding stage conversion through distribution functions. The authors reported that there were few optimal structures for the flotation systems.

Equipment selection has been investigated in a few works. Schena et al. [9] used a series of generic superstructures to represent the equipment, including bank cells and grinding units. However, the grinding units were fixed to reduce the mathematical complexity of the problem. Later, Cisternas et al. [10] utilized a hierarchized superstructure to select bank and column flotation units. However, fixed values of stage recoveries were utilized to avoid a mixed-integer non-convex non-linear problem. Later, Méndez et al. [11] included the selection of grinding stages in the design of a flotation circuit. Again, the grinding unit types were fixed to solve the optimization problem.

On the other hand, uncertainty is inherent in industrial processes, including flotation systems. The effect of uncertainty on the metallurgical behavior of flotation systems could be critical, affecting the economic performance. Several approaches have been proposed in the literature to deal with this uncertainty [12]; e.g., Cisternas et al. [4] and Montenegro et al. [13] used stochastic programming to develop a procedure based on an MILP model to design flotation circuits in which the recoveries in the flotation stages were described by distribution functions. Jamett et al. [14] also applied stochastic programming to design flotation circuits. They used a bank model and limited instances during the design procedure to reduce the computational effort, and consequently the global optimum was not obtained. Liang et al. [15] proposed a framework for the design and optimization of flotation circuits by using the distribution profiles of economic performance. Two sources of uncertainties were considered: first, the copper price and the feed stream; second, the kinetic parameters of the flotation cell model. To solve the MINLP problem under uncertainty, the fuzzy distributional robust optimization method based on possibility and necessity theories was implemented. However, these works neither considered the selection of flotation equipment nor grinding stages, which are essential aspects of industrial practice. Unlike these previous works, Acosta-Flores et al. [8] included uncertainty in the flotation and grinding stages via the distribution functions and consequently in the design of flotation systems. However, they did not consider the selection of flotation equipment and did not study the effect of metal price on the flotation system's design. According to Cisternas et al. [2,16], the metal price influences the structure of flotation circuits and thus must be thoroughly addressed during the design stage. Therefore, equipment selection, metal price uncertainty, and flotation and grinding stage uncertainty often are not studied as a whole during the design of flotation systems, as evidenced in works cited earlier and in other existing studies in the available literature (Table 1).

Another approach proposed in the literature to address the uncertainty in processes is flexibility and resilience, which are significant components of the operability of industrial processes; i.e., these are applied after designing the process. Flexibility can be defined as the capability to adapt to new or changing requirements, whereas resilience can be defined 
as the capability to recover or adjust to misfortune. In this way, flexibility might be better suited for optimists, and resilience might be better for pessimists [17]. These concepts are related to robust optimization; i.e., they provide conservative solutions [18]. In the context of mineral processing, specifically flotation systems, flexibility and resilience have not been applied yet. For this purpose, the required conditions must first be analyzed to guarantee their application.

The basic model used for flexibility considers design variables related to the structure and equipment sizes of the plant, state variables, control state, and uncertain parameters, as well as equations representing the plant performance and constraints representing the operational feasibility. This approach considers a nominal value of the uncertain parameters and the expected deviations to analyze the feasibility of operation via mathematical optimization. In the context of flotation systems, a successful operation depends on the relationship between the recovery and the concentrate grade. The recovery and concentrate grade are opposing but can be included satisfactorily in expressions of economic types, such as the net-smelter-return formula [2]. According to Cisternas et al. [2], the structure is more influential on the economic performance of flotation systems than operational conditions. Thus, a flotation system with a poorly designed structure will be difficult to improve economically under uncertainty, even when modifying the operational conditions. Considering that processing stages exhibit operational uncertainty, a good structure would offer the possibility to establish nominal values for these stages, favoring both the operational feasibility and maximization of revenues generated by the flotation systems.

From the previous literature review, we observed the following: first, the impact of the metal price uncertainty on the design of flotation systems has not been addressed; second, the set of optimal structures for a specific flotation system is small; third, the uncertainty in the species stage recovery has a limited influence on the optimal structures; fourth, the selection of equipment for flotation systems operating under uncertainty has not been thoroughly addressed; and fifth, successful operation is related to the structure of the flotation system. Consequently, the following questions arise:

- Is it possible to determine the structures presenting favorable conditions for operating the flotation systems?

- Does the selection of flotation equipment and metal price influence the operability of the flotation systems?

Thus, the main objective of this work is to establish, from the design point of view, the requirements necessary for the operational feasibility of flotation systems.

\section{Strategy}

A procedure based on mathematical programming and uncertainty analysis is used to address the hypotheses. First, the set of feasible flotation circuit structures to find the optimal structure is represented by a superstructure. This superstructure is utilized to generate a mathematical model, which is used to find the optimal structures. On the other hand, the uncertainty in the variables is represented by distribution functions. Thus, a sample is taken from these distribution functions, and the optimization problem is solved to find the optimal structure. This sampling and optimization process is performed many times to obtain a representative sample of the problem. The results are analyzed to understand the effect of uncertainty (Figure 1). The uncertainty analysis, superstructure representation, modeling, and optimization are briefly described below. 
Table 1. Flotation system design methodologies, NLP = nonlinear programming, $\mathrm{LP}=$ linear programming, and $\mathrm{MINLP}=$ mixed integer nonlinear programming. Uncertainty described by distribution functions.

\begin{tabular}{|c|c|c|c|c|c|}
\hline Reference & Model Type & $\begin{array}{c}\text { Cell/Bank/Approximate } \\
\text { Model }\end{array}$ & Grinding & $\begin{array}{l}\text { Operational and } \\
\text { Metal Price } \\
\text { Uncertainty }\end{array}$ & $\begin{array}{l}\text { Selection of } \\
\text { Flotation } \\
\text { Equipment }\end{array}$ \\
\hline Mehrotra and Kapur, 1974 [19] & NLP & Bank & No & $\mathrm{No}-\mathrm{No}$ & No \\
\hline Reuter et al., 1988 [20] & LP & Bank & No & No-No & No \\
\hline Reuter and Van Deventer, 1990 [21] & LP & Bank & Yes & No-No & No \\
\hline Schena et al., 1996 [22] & MINLP & Bank & Yes & $\mathrm{No}-\mathrm{No}$ & No \\
\hline Schena et al., 1997 [9] & MINLP & Bank & No & $\mathrm{No}-\mathrm{No}$ & No \\
\hline Guria et al., 2005 [23] & NLP & Cell & No & $\mathrm{No}-\mathrm{No}$ & No \\
\hline Guria et al., 2005 [24] & NLP & Cell & No & $\mathrm{No}-\mathrm{No}$ & No \\
\hline Cisternas et al., 2006 [10] & MINLP & Bank & Yes & $\mathrm{No}-\mathrm{No}$ & Yes \\
\hline Méndez et al., 2009 [25] & MINLP & Bank & Yes & $\mathrm{No}-\mathrm{No}$ & Yes \\
\hline Ghobadi et al., 2011 [26] & MINLP & Bank & No & $\mathrm{No}-\mathrm{No}$ & No \\
\hline Maldonado et al., 2011 [27] & NLP & Bank & No & No-No & No \\
\hline Hu et al., 2013 [1] & MINLP & Cell & No & $\mathrm{No}-\mathrm{No}$ & No \\
\hline Montenegro et al., 2013 [13] & MILP & Approximate & No & Yes-No & No \\
\hline Cisternas et al., 2014 [16] & MINLP & Bank & No & $\mathrm{No}-\mathrm{No}$ & No \\
\hline Jamett et al., 2015 [14] & MINLP & Bank & No & Yes-No & No \\
\hline Cisternas et al., 2015 [4] & MILP & Approximate & No & Yes-No & No \\
\hline Acosta-Flores et al., 2018 [7] & MINLP & Bank-Cell & No & $\mathrm{No}-\mathrm{No}$ & No \\
\hline Lucay et al., 2019 [28] & MINLP & Bank & No & No-No & No \\
\hline Liang et al., 2020 [15] & MINLP & Cell & No & Yes-No & No \\
\hline Acosta-Flores et al., 2020 [8] & MILP & Approximate & Yes & Yes-No & No \\
\hline
\end{tabular}
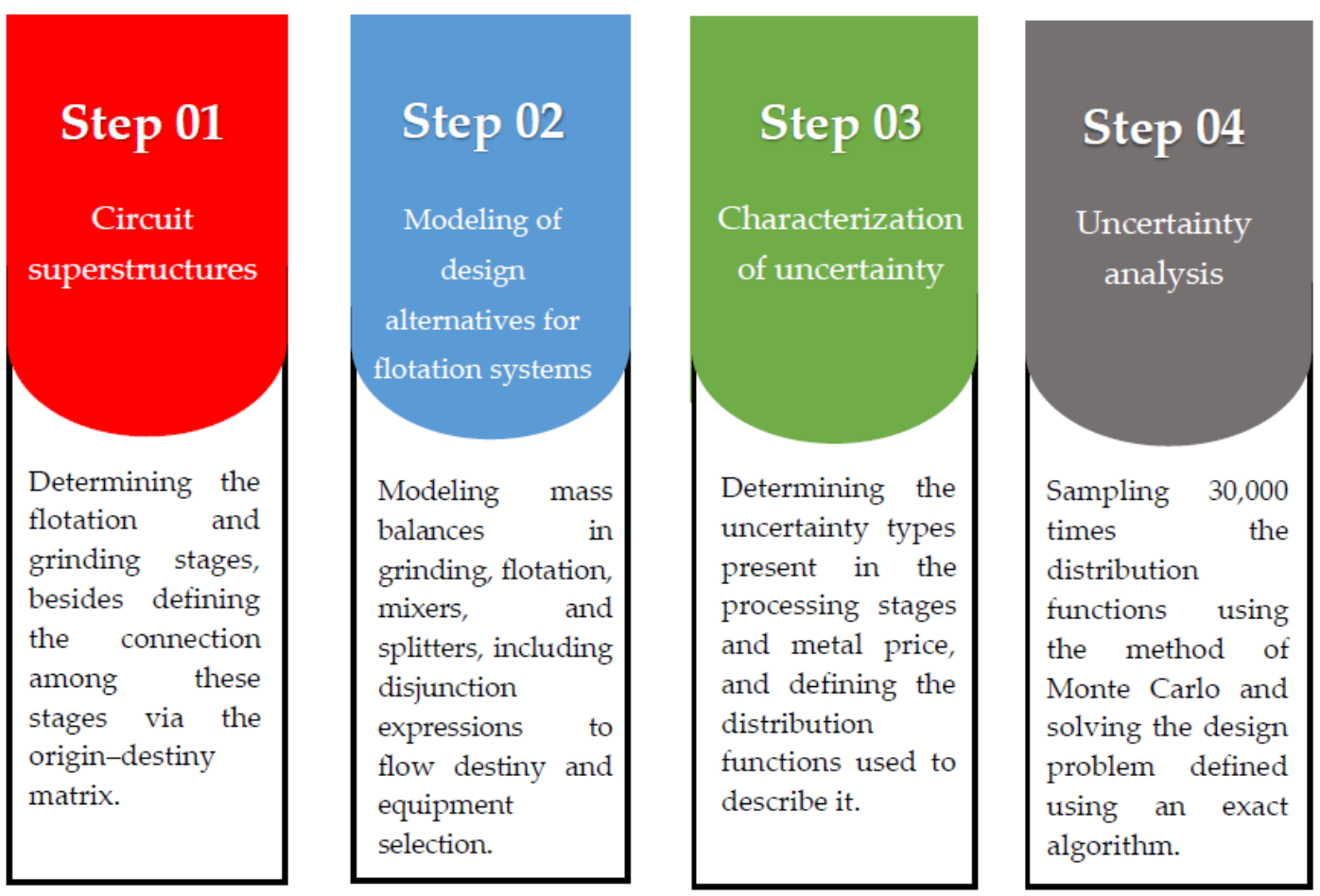

Figure 1. The methodology employed to prove the hypotheses.

\subsection{Uncertainty Analysis (UA)}

During the construction of a mathematical model, several aspects must be specified, including the type and structure of the model, parameters, resolution, and calibration data, among others. Each of these aspects has an associated uncertainty; i.e., an assumption generating uncertainty in the model responses. The uncertainty can be classified as either stochastic and epistemic [29-31]. The first is also referred to as variability, irreducible uncertainty, inherent uncertainty, or uncertainty due to chance. This type of uncertainty is related to variation, which is inherent to a given system, typically as a result of the 
random nature of model inputs, such as the feed grade and the metal price. The second is also referred to as reducible uncertainty, subjective uncertainty, or uncertainty due to lack of knowledge. This type of uncertainty as a resource of non-deterministic behavior derives from a lack of knowledge of the system or the environment, such as the recovery in flotation stages and the conversion in grinding. Both types of uncertainties can be modeled as random variables described by probability distributions.

The uncertainty analysis (UA) allows the uncertainty of the model responses as a result of the uncertainty of model inputs to be quantified. UA can be performed in four steps: first, the uncertainty of input variables must be described through probability distributions; second, samples are generated from the probability distributions via the Monte Carlo method; third, the values of the output variables for each element of the sample are determined; and fourth, the results are analyzed using descriptive statistics. The mathematical model subjected to UA was developed using a methodology based on mathematical programming, as described below.

\subsection{Superstructure}

A superstructure represents a set of structure alternatives where the optimal solution is sought. These structures can represent the equipment, tasks, or states. For example, equilibrium states were utilized in searching for the optimal structure for separation using fractional crystallization [32]. In contrast, Gálvez et al. [33] and Trujillo et al. [34] employed an equipment superstructure to represent superstructures for dewatering and heap leaching design, respectively. The nature of the flotation problem facilitates the use of equipment or stage superstructures to represent the configuration alternatives of the flotation systems. This approach considers the connection between the processing stages, mixers, and splitters. The processing stages include flotation and grinding; mixers are used to mix the feed entering to a processing stage, and splitters are used to send the flows of one stage to another. The connection between all stages implies the degeneration of the design problem; i.e., the appearance of illogical structures and/or defining the same structures two or more times. In this work, to avoid these degenerations, an origin-destination matrix was applied [16].

\subsection{Modeling of Design Alternatives}

The input variables of the mathematical model include the flotation stage recoveries, grinding stage conversion fractions, and metal price. These input variables exhibit uncertainty modeled through distribution functions. The mathematical model includes mass balances in the flotation stages, grinding stages, mixers, and splitters. The objective function is revenue maximization, where the revenue is calculated using the net-smelter-return formula [2]. The revenue is an appropriate objective function for this type of problem [16]. Both the stream interconnection from one stage to another and flotation equipment selection can be modeled by disjunctive equations, which, together with the linear nature of the objective function and mass balances, result in a MILP problem. The modeling of design alternatives is shown above.

Definition of sets: The main sets are

$$
\begin{gathered}
S=\{s / s \text { is stream in the superstructure }\} \\
L C=\{s / s \text { is concentrate stream, } s \in S\} \\
L T=\{s / s \text { is tail stream, } s \in S\} \\
E=\{e / e \text { is flotation stage, grinding stage, splitter, mixer }\} \\
D=\{d / d \text { is splitter }\} \\
K=\{k / k \text { is composition class in the feed }\} \\
J=\{j / j \text { is granulometric class }\}
\end{gathered}
$$


$K_{1}=\left\{\left(k_{1}, k\right) / k_{1}\right.$ is origin composition and $k$ is the destination composition, $\left.k, k_{1} \in K\right\}$

$K_{2}=\left\{\left(k, k_{2}\right) / k\right.$ is origin composition and $k_{2}$ is the destination composition, $\left.k, k_{2} \in K\right\}$

$J_{1}=\left\{\left(j_{1}, j\right) / j_{1}\right.$ is the same size or largest size range than $\left.j, j_{1}>j, j, j_{1} \in J\right\}$

$J_{2}=\left\{\left(j, j_{2}\right) / j_{2}\right.$ is the same size or smallest size range than $\left.j, j_{2}<j, j_{,} j_{2} \in J\right\}$

$I N(e)=\{i / i$ is mass stream entering to processing stage $e \in E\}$

$\operatorname{OUT}(e)=\{i / i$ is mass stream outing from processing stage $e \in E\}$

Each stream $s \in S$ is associated with the variable

$$
W(s, k, j)=\left\{\begin{array}{l}
W_{c}(s, k, j) \text { where } s \in L C \\
W_{t}(s, k, j) \text { where } s \in L T
\end{array}\right.
$$

where $W(s, k, j)$ represents the mass flow rate of class $k$ of size $j$ in stream $s$. The mass flow rate of species $k$ of size $j$ fed to the flotation system, $W_{f}(k, j)$, is a parameter, and thus the values are known.

Mass balance in flotation stage, splitters, and mixers: The following equation provides the mass balance in the flotation stage, splitters, and mixers:

$$
\sum_{s \in I N(e)} W(s, k, j)=\sum_{l \in \text { OUT(e) }} W(l, k, j), k \in K, j \in J, e \in E
$$

Flotation balance: The following equations provide the concentrate and tail streams, respectively, generated by a flotation stage:

$$
\begin{aligned}
& W C(e, k, j)=\sum_{l \in \text { OUT }(e)} W_{c}(l, k, j), k \in K, j \in J, e \in E \\
& W T(e, k, j)=\sum_{l \in \text { OUT }(e)} W_{t}(l, k, j), k \in K, j \in J, e \in E
\end{aligned}
$$

where

$$
\begin{gathered}
W_{c}(l, k, j)=T(e, k, j) \cdot F S(e, k, j), \quad l \in \operatorname{OUT}(e), e \in E \\
W_{t}(l, k, j)=(1-T(e, k, j)) \cdot F S(e, k, j), \quad l \in \operatorname{OUT}(e), e \in E \\
F S(e, k, j)=\sum_{s \in I N(e)} W(s, k, j) \\
F S(e, k, j)=W C(e, k, j)+W T(e, k, j)
\end{gathered}
$$

where $W(s, k, j)$ is the mass flow rate of specie $k$ of size $j$ in stream $s$ entering flotation stage $e, W_{c}(l, k, j)$ is the concentrate mass flow rate of specie $k$ of size $j$ in stream $l$ exiting from flotation stage $e, W_{t}(l, k, j)$ is the tail mass flow rate of specie $k$ of size $j$ in stream $l$ exiting from flotation stage $e$, and $T(e, k, j)$ represents the recovery of class $k$ of size $j$ in flotation stage $e$. In this work, the latter will be represented by distribution functions.

Mass balance in grinding: The following equations provide the mass balance by grinding stages:

$$
\sum_{s \in I N(e)} \sum_{(k, j) \in(K, J)} W(s, k, j)=\sum_{l \in O U T(e)} \sum_{(k, j) \in(K, J)} W(l, k, j), \quad e \in E
$$

where $W(s, k, j)$ is the mass flow rate of specie $k$ of size $j$ in stream $s$ entering grinding stage $e$, and $W(l, k, j)$ is mass flow rate of specie $k$ of size $j$ in stream $l$ exiting from grinding stage e. In this work, the latter is estimated by the following linear model [26]:

$$
W(l, k, j)=W(s, k, j)+\tau \sum_{\left(k_{1}, j_{1}\right) \in\left(K_{1}, J_{1}\right)} \phi_{k 1, j 1}^{k, j} W\left(i, k_{1}, j_{1}\right)-\tau \sum_{\left(k_{2}, j_{2}\right) \in\left(K_{2}, J_{2}\right)} \phi_{k, j}^{k 2, j 2} W(i, k, j)
$$


where $\tau$ is the residence time of feed in the grinding, and $\phi_{k 1, j 1}^{k, j}$ and $\phi_{k, j}^{k 2, j 2}$ are denominated as transference functions. The grinding makes either a fraction or all particles from class $\left(k_{1}, j_{1}\right)$ transformed into material belonging to class $(k, j)$, and, simultaneously, either a fraction or all of the particles in class $(k, j)$ are transformed into a material belonging to class $\left(k_{2}, j_{2}\right)$. These transformations of material are described by distribution functions.

Disjunction in splitters: The mass flow rate entering splitter $d$ can be sent to different destinations, where the selection of a destination annuls the other destinations. This can be expressed via the following equations:

$$
\begin{gathered}
\sum_{l \in \operatorname{OUT}(d)} \sum_{(k, j) \in(K, J)} W(l, k, j)=W(d), d \in D, l \in \operatorname{OUT}(d), d \in D \subset E \\
\sum_{(k, j) \in(K, J)} W(l, k, j) \leq M \cdot Y(d, l), d \in D, l \in \operatorname{OUT}(d), d \in D \subset E \\
\sum_{l \in \text { OUT }(d)} Y(d, l) \leq Y D(d)
\end{gathered}
$$

where $Y D(d)$ is a binary variable indicating the existence of splitter $d$, and $Y(d, l)$ is a binary variable indicating the destination of the mass flow, $W(d)$, leaving splitter $d$. $M$ indicates the upper bound of $W(d)$.

Equipment selection: The cleaner and recleaner stages can include cell bank or flotation columns. The selection of equipment can be expressed via the following equations:

$$
\begin{gathered}
Y_{\text {Col1 }}+Y_{\text {Cell1 }}=Y_{\text {cleaner }} \\
Y_{\text {Col2 }}+Y_{\text {Cell2 }}=Y_{\text {recleaner }}
\end{gathered}
$$

where $Y_{\mathrm{Col1}}$ is a binary variable indicating the selection of columns in the cleaner stage, $Y_{\text {Cell1 }}$ is a binary variable indicating the selection of cell banks in the cleaner stage, $Y_{\text {cleaner }}$ is a binary variable indicating the existence of a cleaner stage, $Y_{\text {Col2 }}$ is a binary variable indicating the selection of columns in the recleaner stage, $Y_{\text {Cell2 }}$ is a binary variable indicating the selection of cell banks in the recleaner stage, and $Y_{\text {recleaner }}$ is a binary variable indicating the existence of a recleaner stage.

Metallurgical parameters: The following equations provide the mass flow rate and grade of concentrate, respectively, generated by the flotation systems:

$$
\begin{gathered}
C F=\sum_{l \in I N(P)} \sum_{(k, j) \in(K, J)} W_{c}(l, k, j) \\
\text { grade }=\frac{\sum_{l \in I N(P)} \sum_{(k, j) \in(K, J)} W_{c}(l, k, j) g(k, j, c u)}{\sum_{l \in I N(P)} \sum_{(k, j) \in(K, J)} W_{c}(l, k, j)}
\end{gathered}
$$

where $g(k, j, c u)$ is the copper grade of class $k$ of size $j$, and $P$ represents the final concentrate.

Objective function: In this work, the objective function is given by

$$
\text { Revenue }=C F[p(\text { grade }-\mu)(q-R f c)-\operatorname{Trc}] H
$$

where $p$ is the fraction of metal paid, $\mu$ is the grade deduction, $\operatorname{Tr} c$ is the treatment charge, $q$ is the metal price, $R f c$ is the refinery charge, and $H$ represents the annual operational hours.

\subsection{Optimization Algorithms}

The optimization algorithms can be divided into exact and approximate methods [35]. In this work, exact methods were implemented to solve the design problem. These algorithms obtain an optimal solution and guarantee its optimality. Specifically, the algorithms implement the problem's analytical properties to generate a sequence of points converging 
to a globally optimal solution. The related literature highlights several solvers to address the MILP model; for example, the CPLEX solver.

\section{Applications}

The methodology previously defined was applied to design structures for flotation systems and, consequently, to prove the hypotheses. Initially, the processed feed considered nine species, characterized by three main components: $9 \mathrm{t} / \mathrm{h}$ of chalcopyrite with $33 \%$ copper, $23 \mathrm{t} / \mathrm{h}$ of mixed mineral with $17 \%$ copper, and $350 \mathrm{t} / \mathrm{h}$ of gangue with $0 \%$ copper, where each of these main components includes three particle sizes. The superstructure implemented consisted of the following stages: Rougher $(R)$, Cleaner1 $\left(C_{1}\right)$, Cleaner2 $\left(C_{2}\right)$, Scavenger1 $\left(S_{1}\right)$, Scavenger2 $\left(S_{2}\right)$, Cleaner-Scavenger $(C S)$, Regrinding1 $\left(G r_{1}\right)$, and Regrinding2 $\left(\mathrm{Gr}_{2}\right)$. The connections between the stages considered are described by the origin-destination matrix shown in Table 2. In Table 2, " $\mathrm{x}$ " and " $\mathrm{o}$ " represent tails and concentrate streams, respectively. For example, the concentrate from Cleaner1 $\left(C_{1}\right)$ can be sent to $C_{2}$ or become the product $P$, whereas the tails can be sent to the stages $R, S_{1}, G r_{2}$, and $C S$.

Table 2. Origin-destination matrix for concentrates (o) and tails (x) of flotation system.

\begin{tabular}{|c|c|c|c|c|c|c|c|c|c|c|}
\hline Stages & $R$ & $G r_{1}$ & $C_{1}$ & $C_{2}$ & $S_{1}$ & $S_{2}$ & $G r_{2}$ & $C S$ & $W$ & $P$ \\
\hline$R$ & & o & $\mathrm{o}$ & & $x$ & & & & & \\
\hline$G r_{1}$ & & & $\mathrm{o}$ & & & & & $\mathrm{o}$ & & \\
\hline$C_{1}$ & $x$ & & & o & $x$ & & $x$ & $x$ & & $\mathrm{o}$ \\
\hline$C_{2}$ & & $x$ & & & $x$ & & $x$ & $x$ & & $\mathrm{o}$ \\
\hline$S_{1}$ & o & o & o & o & & $x$ & o & $\mathrm{o}$ & & \\
\hline$S_{2}$ & & o & $\mathrm{o}$ & o & & & o & $\mathrm{o}$ & $x$ & \\
\hline$G r_{2}$ & & & o & o & o & $\mathrm{o}$ & & $\mathrm{o}$ & & \\
\hline$C S$ & $\mathrm{o}$ & & & $x$ & $\mathrm{O}$ & & & & & $\mathrm{o}$ \\
\hline
\end{tabular}

In Table 2, the symbols $W$ and $P$ represent the final tail and final concentrate, respectively. The origin-destination matrix represents a total of 21,600 flotation circuit structures. There are 120 input variables of the mathematical model, of which 72 are related to flotation stages and 48 are connected to grinding stages. The variables exhibit epistemic uncertainty due to the insufficient quantity of information and, according to the principle of indifference, can be described using uniform distribution functions [30]. Tables 3-5 give the uniform distribution function for the flotation stage (Table 3) and grinding stages (Tables 4 and 5). Here, the standard notation for the uniform distribution is utilized, which is $X \sim U(a, b)$, where $a$ and $b$ are the lowest and highest values of $x$, respectively. The copper price exhibits stochastic uncertainty due to its unpredictable nature and according to [36] must be described by the uniform distribution function. Standard operational conditions of grinding and flotation stages were extracted from the works reported in Table 1. Subsequently, these values were used to define ranges of uncertainty in each process and for each mineralogical species. For example, the recovery of chalcopyrite ore with an average size exhibits a good recovery in the rougher stage. Thus, in this work, this was taken as being equal to 0.9 . Based on this latter value, variations of $\pm 5 \%$ was considered, obtaining the range shown in Table 3. 
Table 3. Recovery in flotation stages, range of uncertainty $U(a, b)$.

\begin{tabular}{cccccccccc}
\hline Stages & CPY.f1 & CPY.f2 & CPY.f3 & MIX.f1 & MIX.f2 & MIX.f3 & SC.f1 & SC.f2 & SC.f3 \\
\hline R & $(0.665,0.735)$ & $(0.855,0.945)$ & $(0.760,0.840)$ & $(0.380,0.420)$ & $(0.665,0.735)$ & $(0.570,0.630)$ & $(0.048,0.053)$ & $(0.095,0.105)$ & $(0.048,0.053)$ \\
C1, cell & $(0.475,0.525)$ & $(0.665,0.735)$ & $(0.475,0.525)$ & $(0.190,0.210)$ & $(0.475,0.525)$ & $(0.285,0.315)$ & $(0.048,0.053)$ & $(0.057,0.063)$ & $(0.048,0.053)$ \\
C2, cell & $(0.475,0.525)$ & $(0.665,0.735)$ & $(0.475,0.525)$ & $(0.190,0.210)$ & $(0.475,0.525)$ & $(0.285,0.315)$ & $(0.048,0.053)$ & $(0.057,0.063)$ & $(0.048,0.053)$ \\
C1, col & $(0.285,0.315)$ & $(0.380,0.420)$ & $(0.285,0.315)$ & $(0.190,0.210)$ & $(0.285,0.315)$ & $(0.190,0.210)$ & $(0.024,0.026)$ & $(0.024,0.026)$ & $(0.024,0.026)$ \\
C2, col & $(0.285,0.315)$ & $(0.380,0.420)$ & $(0.285,0.315)$ & $(0.190,0.210)$ & $(0.285,0.315)$ & $(0.190,0.210)$ & $(0.024,0.026)$ & $(0.024,0.026)$ & $(0.024,0.026)$ \\
S1 & $(0.665,0.735)$ & $(0.855,0.945)$ & $(0.760,0.840)$ & $(0.380,0.420)$ & $(0.665,0.735)$ & $(, 0570,0.630)$ & $(0.048,0.053)$ & $(0.095,0.105)$ & $(0.048,0.053)$ \\
S2 & $(0.665,0.735)$ & $(0.855,0.945)$ & $(0.760,0.840)$ & $(0.380,0.420)$ & $(0.665,0.735)$ & $(, 0570,0.630)$ & $(0.095,0.105)$ & $(0.190,0.210)$ & $(0.095,0.105)$ \\
CS & $(0.665,0.735)$ & $(0.855,0.945)$ & $(0.760,0.840)$ & $(0.380,0.420)$ & $(0.665,0.735)$ & $(, 0570,0.630)$ & $(0.095,0.105)$ & $(0.190,0.210)$ & $(0.095,0.105)$ \\
\hline
\end{tabular}

Table 4. Conversion in grinding 1 , range of uncertainty $U(a, b)$.

\begin{tabular}{|c|c|c|c|c|c|c|c|c|c|}
\hline & CPY.f1 & CPY.f2 & CPY.f3 & MIX.f1 & MIX.f2 & MIX.f3 & SC.f1 & SC.f2 & SC.f3 \\
\hline CPY.f1 & $(0.05,0.15)$ & $(0.35,0.45)$ & $(0.45,0.55)$ & & & & & & \\
\hline CPY.f2 & & $(0.15,0.25)$ & $(0.75,0.85)$ & & & & & & \\
\hline CPY.f3 & & & 1 & & & & & & \\
\hline MIX.f1 & & $(0.05,0.15)$ & $(0.05,0.15)$ & $(0.25,0.30)$ & $(0.25,0.30)$ & $(0.05,0.15)$ & $(0.00,0.10)$ & $(0.00,0.075)$ & $(0.00,0.075)$ \\
\hline MIX.f2 & & & $(0.05,0.15)$ & & $(0.55,0.65)$ & $(0.05,0.15)$ & & $(0.15,0.25)$ & \\
\hline MIX.f3 & & & & & & 1 & & & \\
\hline SC.f1 & & & & & & & 1 & & \\
\hline SC.f2 & & & & & & & & $(0.190,0.210)$ & $(0.095,0.105)$ \\
\hline
\end{tabular}

Table 5. Conversion in grinding 2 , range of uncertainty $\mathrm{U}(\mathrm{a}, \mathrm{b})$.

\begin{tabular}{|c|c|c|c|c|c|c|c|c|c|}
\hline & CPY.f1 & CPY.f2 & CPY.f3 & MIX.f1 & MIX.f2 & MIX.f3 & SC.f1 & SC.f2 & SC.f3 \\
\hline CPY.f1 & $(0.048,0.053)$ & $(0.285,0.315)$ & $(0.615,0.682)$ & & & & & & \\
\hline CPY.f2 & & $(0.285,0.315)$ & $(0.665,0.735)$ & & & & & & \\
\hline CPY.f3 & & & 1 & & & & & & \\
\hline MIX.f1 & & $(0.19,0.21)$ & $(0.19,0.21)$ & $(0.095,0.105)$ & $(0.19,0.21)$ & $(0.19,0.21)$ & $(0.0475,0.0525$ & $(0.0237,0.0262)$ & $(0.0237,0.0262)$ \\
\hline MIX.f2 & & $(0.095,0.105)$ & $(0.285,0.315)$ & & $(0.095,0.105)$ & $(0.21,0.19)$ & & $(0.19,0.21)$ & $(0.095,0.105)$ \\
\hline MIX.f3 & & & $(0.19,0.21)$ & & & $(0.38,0.42)$ & & & $(0.38,0.42)$ \\
\hline SC.f1 & & & & & & & $(0.095,0.105)$ & $(0.38,0.42)$ & $(0.475,0.525)$ \\
\hline SC.f2 & & & & & & & & $(0.665,0.735)$ & $(0.285,0.315)$ \\
\hline
\end{tabular}

\subsection{Uncertainty in Grinding and Flotation Stages, and the Selection of Equipment in the Recleaner Stage}

In this first instance, the model considers uncertainty in the processing stages and selects flotation equipment in the recleaner stage. Three scenarios were studied: the first considered the fixed copper price; the second considered a description of the copper price of $\mathrm{U}[3000,4000] \mathrm{USD} / \mathrm{t}$, and the third considered a representation of the copper price of $\mathrm{U}[5000,7000] \mathrm{USD} / \mathrm{t}$. The code was developed in GAMS, using a laptop with Intel Core i7 2.21 GHz and 16 GB of RAM. The code was evaluated 30,000 times (samples from the distribution functions) for each scenario, and the results obtained are shown below.

Figure 2 shows the structures of the flotation systems obtained by solving the MILP model using the fixed copper price. Seven structures arose from a total of 21,600 possibilities, with structure 1 (43.2\%) and structure 2 (49.5\%) predominating, as shown in Figure 3. Here, only five optimal structures are shown because the other structures exhibited a low percentage appearance related to the operational conditions outlier, resulting in a degeneration of the design problem. Structures 1 and 2 are configurations that allow for the maximization of revenues in a wide range of values for recoveries and conversions in the flotation and grinding stages, respectively. This characteristic means that structures 1 and 2 offer a wide range of nominal values for the processing stages, around which it is possible to define constraints representing the operational feasibility of flotation systems. Thus, these results indicate that few structures exhibit favorable conditions to face uncertainty and, consequently, conditions favoring both the operational feasibility and maximization of the revenues generated. Figure 2 indicates that the selection of equipment influences the capacity to face the uncertainty by the optimal structures. Structure 1 exhibits a better 
capability to adapt to new situations when using the flotation columns in the recleaner stage, whereas structure 2 presents a better capacity to face operational changes when using the cell banks in the recleaner stage. The difference between structures 1 and 2 is that the first sends the concentrate of the cleaner-scavenger stage to the cleaner stage, whereas the second sends the concentrate of the cleaner-scavenger stage to the recleaner stage. This difference means that the recleaner stage receives a feeding with different metallurgical characteristics. In structure 1, those characteristics are improved by implementing cell banks favoring the recoveries of classes containing valuable species, whereas in the case of structure 2, those characteristics are improved by using flotation columns favoring an increase in the concentrate grade. These structures do not recirculate flows to the rougher stage, reducing the overload of the flotation systems. It is important to indicate that different targets of concentrate grades can also influence structures for flotation systems. Designing structures for flotation systems considering predefined metallurgical parameters is called reverse optimization. This alternative approach makes an MINLP problem more challenging to solve than the MILP model presented in this work.

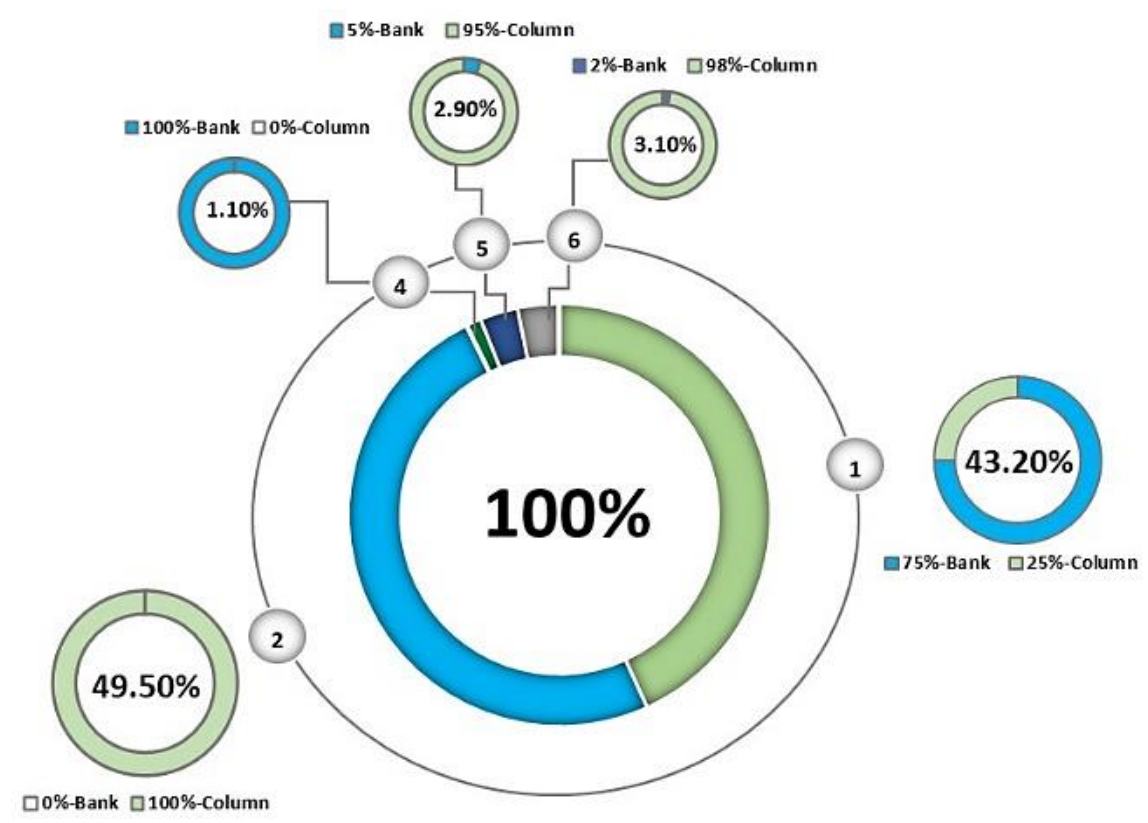

Figure 2. Graphical representation of results obtained by selecting equipment in the recleaner stage, with a copper price equal to $3500 \mathrm{USD} / \mathrm{ton}$.

The effect of no equipment selection was also analyzed; specifically, the design problem was solved considering the following instances: first, the recleaner stage using columns, and second, the recleaner stage using a flotation bank. The results are shown in Figure 4 and reveal that structure 1 was predominant when the recleaner stage implemented cell banks, whereas structure 1 and structure 2 were predominant when the recleaner stage used columns. Thus, the type of flotation equipment used in the recleaner stage influences the optimal structures for flotation systems and consequently their capability to face uncertainty, which is consistent with the previous results. 


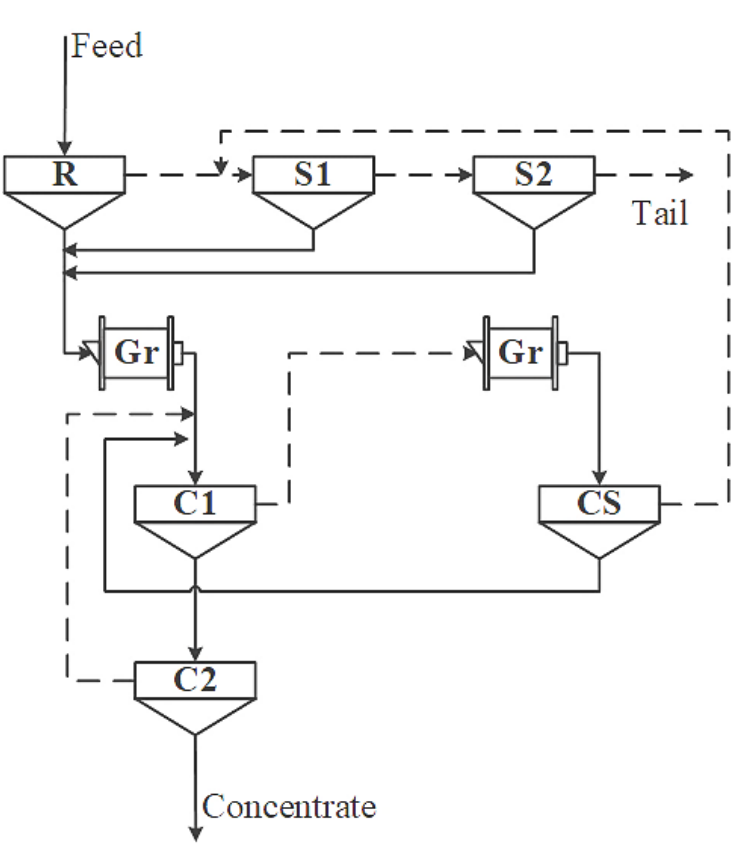

(a)

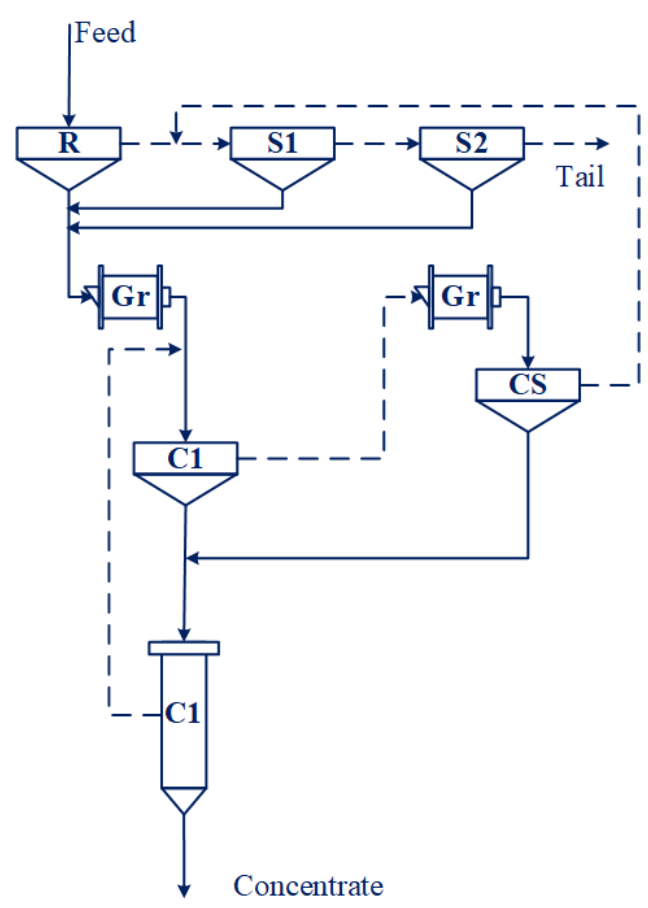

(b)

Figure 3. Predominant structures in each instance: (a) structure 1; (b) structure 2.

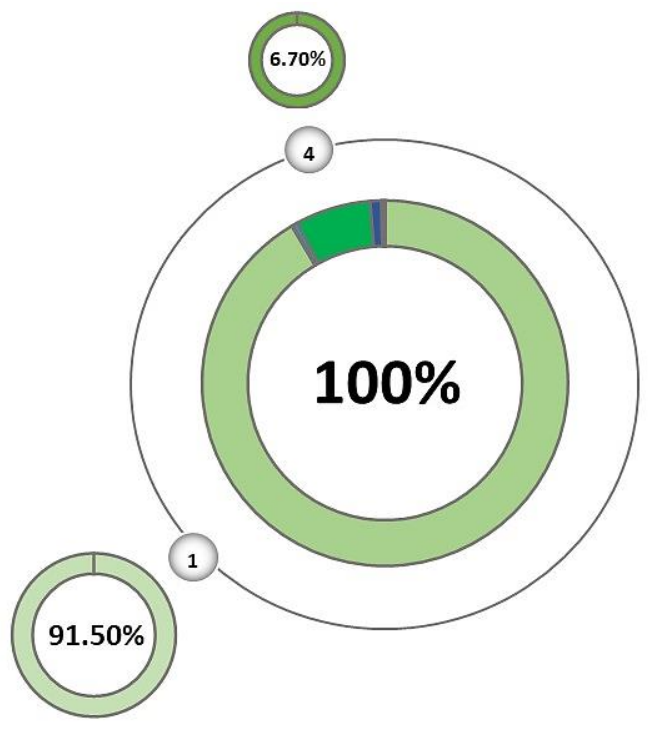

(a)

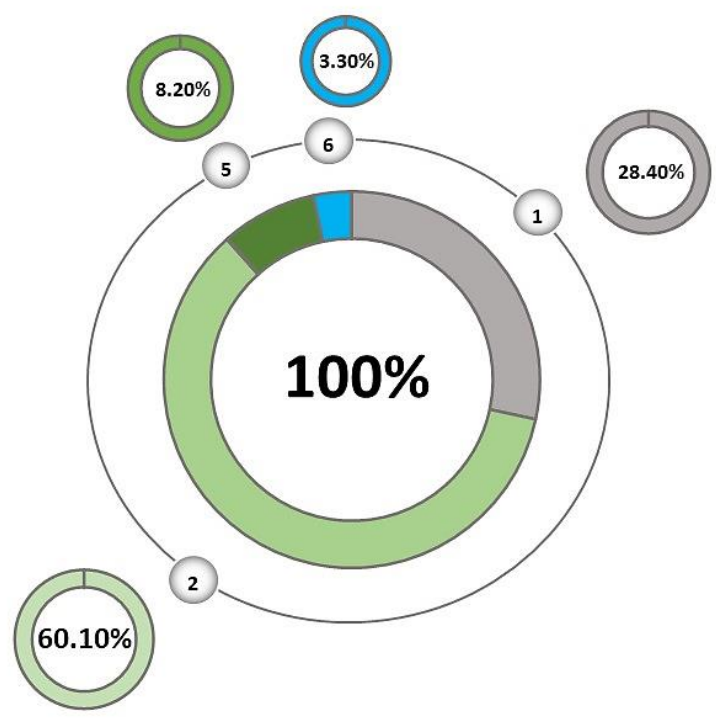

(b)

Figure 4. Graphical representation of results obtained by using a copper price equal to 3500 USD/ton, fixed bank (a) and fixed column (b).

Figure 5a shows the structures for flotation systems provided by the methodology when the copper price exhibits uncertainty as described by U[3000,4000] USD/t. Nine optimal structures were identified, where 3,8 , and 9 can be considered outlier configurations due to their low appearance percentage (not shown). Again, despite uncertainty in the copper price, the methodology indicated that few structures exhibited favorable conditions to face uncertainty and, consequently, conditions favored both the operational feasibility and maximization of revenues. The uncertainty of the copper price slightly modified the results obtained in the first scenario. In fact, despite uncertainty in the copper price, structure 1 
(43.4\%) and structure $2(44.6 \%)$ predominated. The flotation equipment type influenced the optimal structures. In fact, structures 1, 4, 5, and 7 considered selecting equipment, whereas structures 2 and 6 did not consider choosing between columns or cell banks. Structure 1 exhibited a better capability to face operational uncertainty when implementing cell banks $(62 \%)$ compared with flotation columns $(38 \%)$ in the cleaner stage. Structure 2 showed a better capability to adapt to operational uncertainty when implementing flotation columns $(100 \%)$ in the cleaner stage. All the structures obtained considered six flotation stages and two grinding stages. These latter stages improved the liberation of valuable species and the quality of the final concentrate, consequently increasing the revenues.

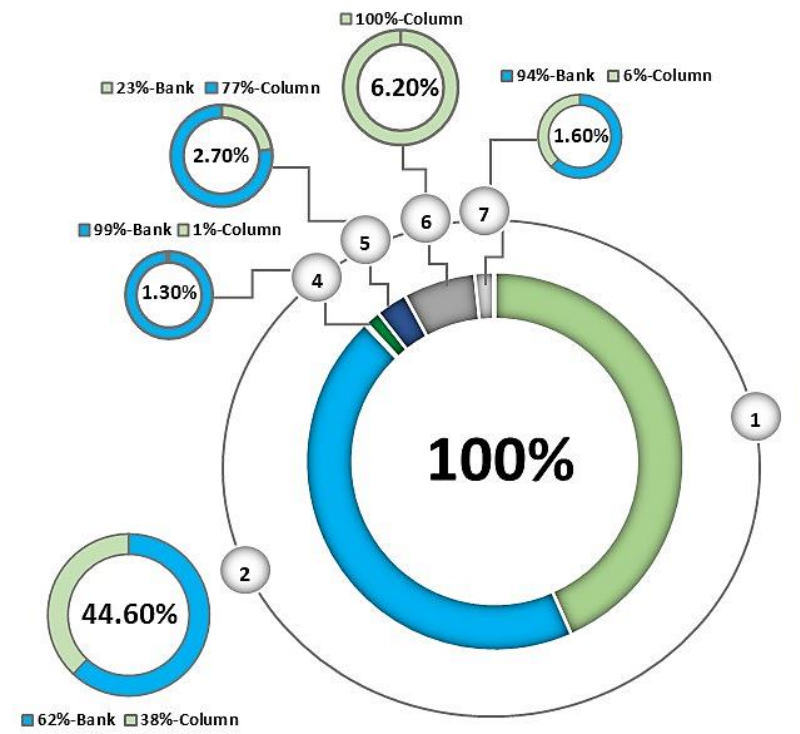

(a)

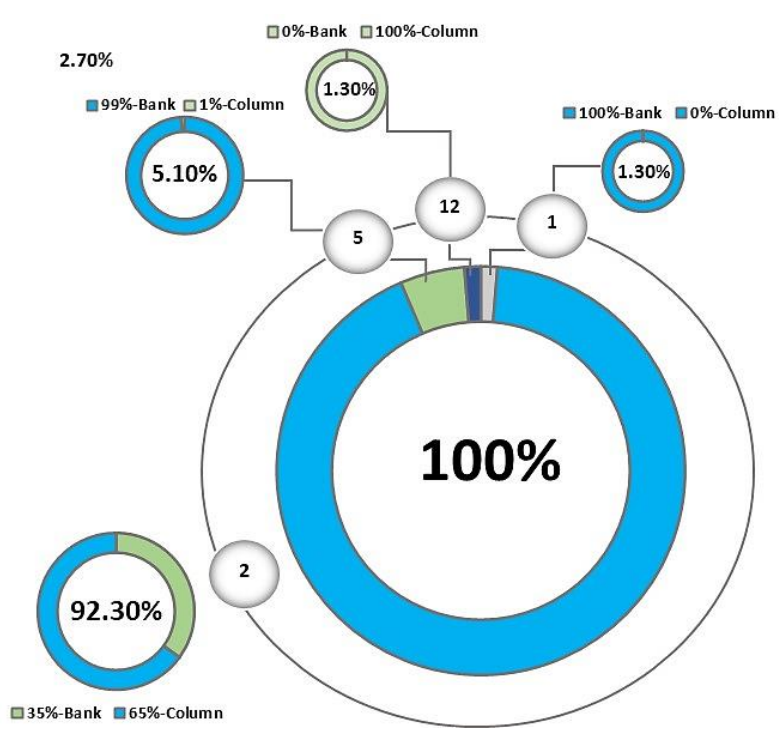

(b)

Figure 5. Graphical representation of the results obtained by selecting equipment in the recleaner stage, (a) copper price uncertainty described by $\mathrm{U}(3000,4000) \mathrm{USD} / \mathrm{t}$, (b) copper price uncertainty $\mathrm{U}(5000,7000) \mathrm{USD} / \mathrm{t}$.

Figure $5 \mathrm{~b}$ also shows the optimal structures of flotation systems provided by the code when the copper price exhibits uncertainty, as described by U[5000,7000] USD/t. In general, structures 1, 5, and 12 did not consider selecting flotation equipment, whereas structure 2 considered selecting between columns and cell banks depending on the operational conditions. A high copper price reduced the number of primal optimal structures-i.e., those obtained when the copper price was described by $\mathrm{U}[3000,4000] \mathrm{USD} / \mathrm{t}$ - and promoted the appearance of new structures. In general, the primal structures with a low percentage of appearance tended to disappear, which could be related to their low capacity to maximize the recovery of classes containing valuable species. Thus, a high copper price reduced the number of structures, favoring both the operational feasibility and maximization of generated revenues. In this scenario, structure 2 was predominant with $92.3 \%$ appearance, which could be attributed to the following: first, this structure provides a high rate of recovery of copper; second, it exhibits flexibility by including columns or cell banks depending on operational conditions; and third, it exhibits robustness to face economic and operational uncertainty.

\subsection{Uncertainty in Regrinding and Flotation Stages and Selection of Equipment in Cleaner and Recleaner Stages}

In this second instance, the design methodology considered uncertainty in the processing stages and equipment selection in the cleaner and recleaner stages. Similarly, three scenarios were analyzed; fixed copper price, uncertainty in copper price characterized by $\mathrm{U}[3000,4000] \mathrm{USD} / \mathrm{t}$, and copper price uncertainty characterized by $\mathrm{U}[5000,7000] \mathrm{USD} / \mathrm{t}$. The following conditions were incorporated in the code: (a) if the cleaner stage implements 
columns, then the recleaner stage must implement columns; and (b) if the cleaner stage implements cell banks, then the recleaner stage can implement cell banks or columns. These conditions were implemented using the logic constraints described in [37]. Again, the code was executed 30,000 times for each scenario, and the results obtained in this instance are shown in Figure 6.

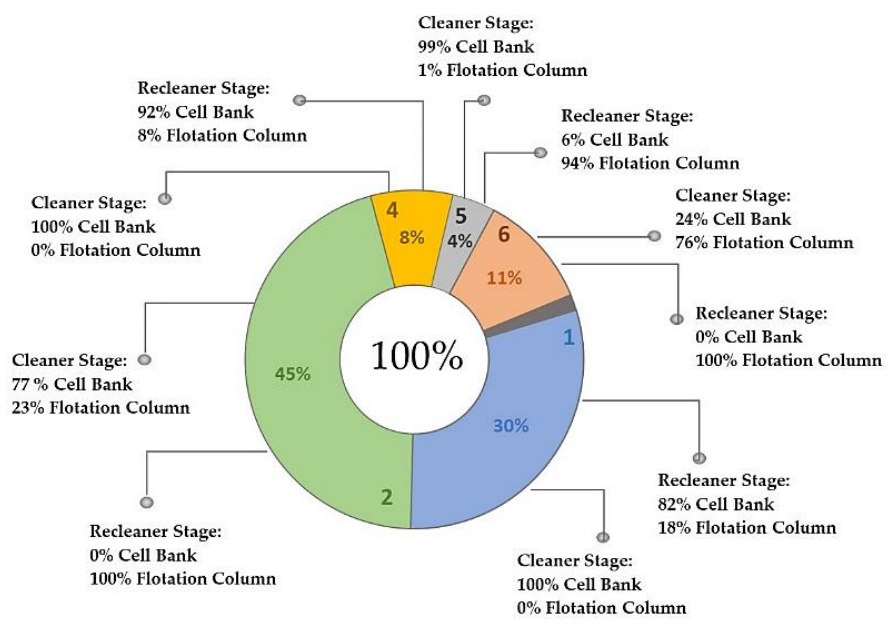

(a)

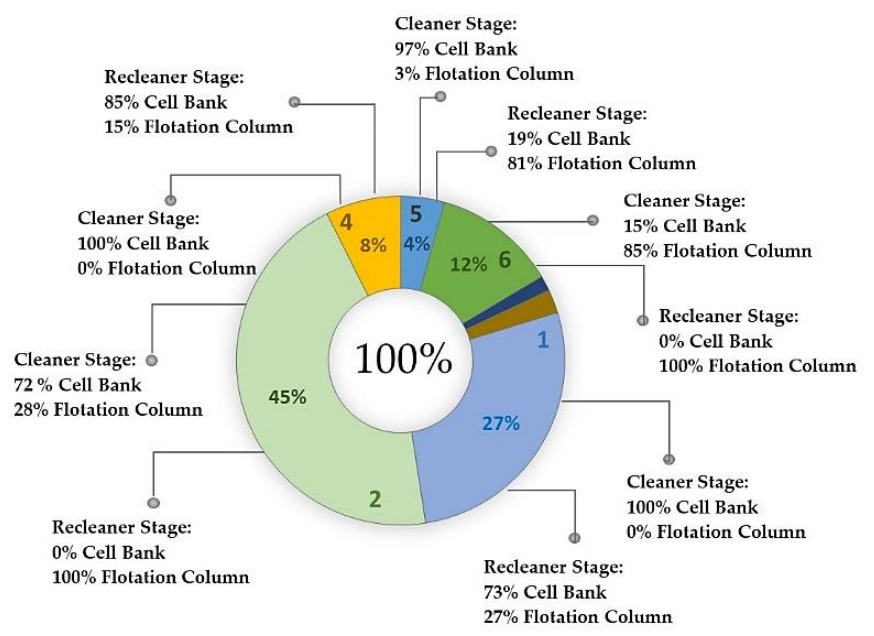

(b)

Figure 6. Graphical representation of the percentage of optimal structures (a) without uncertainty in the copper price, and (b) with a copper price uncertainty described by U[000,000,3,4] USD/t.

Figure 6a shows the structures of flotation systems obtained with a fixed copper price. Nine optimal structures appear in this scenario, with structure $2(45.2 \%)$, structure $1(29.9 \%)$, structure $6(10.9 \%)$, structure $4(7.8 \%)$, and structure $5(4 \%)$ predominating, whereas structures 3,7 , and 8 can be considered as outlier configurations. This figure shows that optimal structures implemented a cell bank or flotation column in cleaner and recleaner stages. For example, structure 1 utilized cell banks in the cleaner and recleaner stages in $100 \%$ and $82 \%$ of the cases studied, respectively. Therefore, in the recleaner stage, flotation columns were utilized in $18 \%$ of the cases studied. This description is performed for other configurations. In the cleaner stage, structure 2, structure 4, structure 5, and structure 6 implemented banks and columns in 77\% and 23\%,100\% and $0 \%, 99 \%$ and 1\%, and $24 \%$ and $76 \%$ of cases, respectively. In the recleaner stage, structure 2 , structure 4 , structure 5, and structure 6 implemented banks and columns in $0 \%$ and $100 \%, 92 \%$ and $8 \%$, $6 \%$ and $94 \%$, and $0 \%$ and $100 \%$ of cases, respectively. Thus, selecting flotation equipment in the cleaner and recleaner stages influenced the optimal flotation structures. Again, the results indicate that few structures exhibited favorable conditions for facing uncertainties, at the same time offering conditions favoring both optimal operation and the maximization of the revenues generated. In industrial practice, structures 1 and 2 are observed. The first structure implemented cell banks in the cleaner and recleaner stages, favoring recovery. This dispositive utilized a mechanic system that generates turbulence, benefiting the contact between particle and bubble and consequently increasing the recovery of species. The second structure implemented flotation columns in the recleaner stage. This equipment exhibited the absence of a mechanic system and the presence of wash water, reducing the entrainment of impurities and consequently increasing the concentrate grade [38].

Figure $6 \mathrm{~b}$ shows the optimal flotation structures provided by the code when the copper price uncertainty was described by U[3000,4000] USD/t. Here, structure 2 (44.9\%), structure $1(27.2 \%)$, structure $6(12.1 \%)$, and structure $4(7.4 \%)$ were predominant. This figure shows that in the cleaner stage, structure 1, structure 2, structure 4, structure 5, structure 5, and structure 6 implemented banks and columns in $100 \%$ and $0 \%, 72 \%$ and $28 \%, 100 \%$ and $0 \%, 97 \%$ and $3 \%$, and $15 \%$ and $85 \%$ of cases, respectively. In the recleaner 
stage, structure 1, structure 2, structure 4, structure 5, and structure 6 implemented banks and columns in $73 \%$ and $27 \%, 0 \%$ and $100 \%, 85 \%$ and $15 \%, 19 \%$ and $81 \%$, and $0 \%$ and $100 \%$ of cases, respectively. Thus, selecting the flotation equipment influenced the optimal structures for flotation systems. Again, the methodology indicates that few structures exhibited favorable conditions to face uncertainty, and consequently conditions favoring both optimal operation and the maximization of revenues were generated. The copper price uncertainty had a slight effect on the predominant optimal structures. Structure 2 preserved the utilization of cell banks or columns in the cleaner stage and columns in the recleaner stage (see Figure 7).

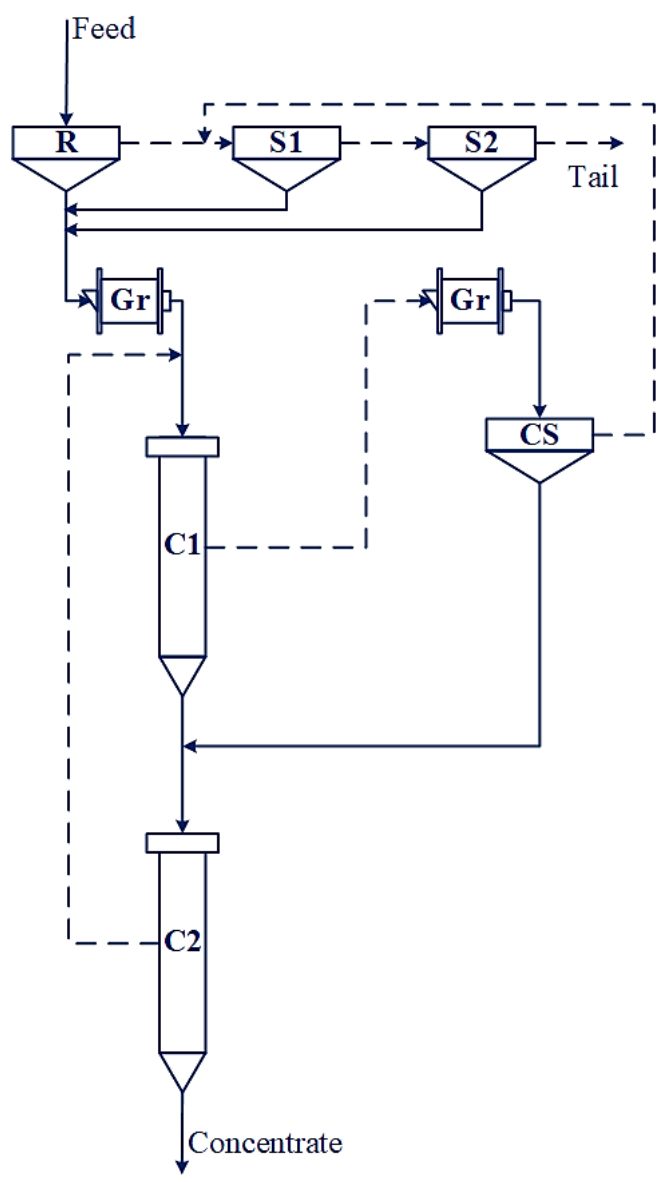

Figure 7. Structure 2 using columns in the cleaner and recleaner stages, with copper price uncertainty described by $\mathrm{U}(3000,4000) \mathrm{USD} / \mathrm{t}$.

Figure 8 shows the optimal structures obtained when the copper price uncertainty was described by U[5000,7000] USD/t. Here, a high copper price reduced the number of primal optimal structures (U[3000,4000] USD/t) and promoted the appearance of new structures. Again, the primal optimal structures with a low percentage of appearance tended to disappear. All structures implemented cell banks in the cleaner stage, perhaps to maximize the recovery of classes containing valuable mineralogical species. Here, structure 2 was predominant with $76.2 \%$ appearance and implemented flotation columns (61\%) and cell banks (39\%) in the recleaner stage. This high percentage of appearance could be attributed to its good capacity for recovery, flexibility, and robustness in facing uncertainty. 


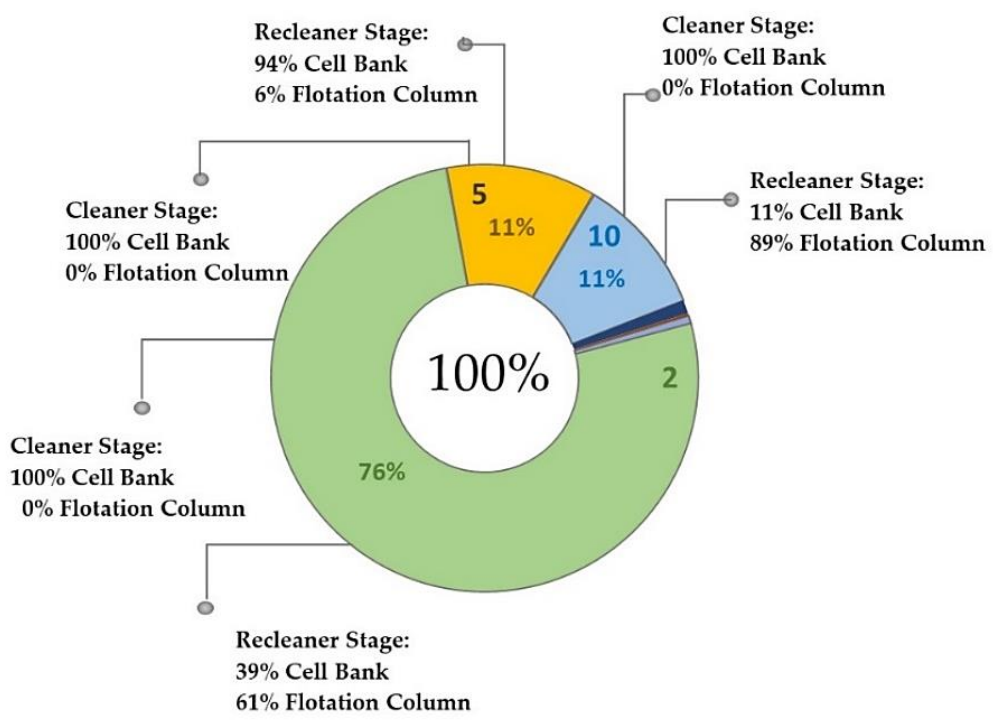

Figure 8. Graphical representation of the percentage of optimal structures considering the selection of equipment in cleaner and recleaner stages, with copper price uncertainty described by $U(5000,7000)$.

The methodology and instances analyzed indicated that few structures exhibited favorable conditions for facing uncertainty. At the same time, these structures offered conditions favoring both optimal operation and the maximization of revenues generated by flotation systems. Such favorable conditions were proportional to the percentage representing structures in the optimal set; i.e., a higher percentage of the structure implied a greater capacity to face operational and metal price changes. In addition, selecting flotation equipment influenced the selection of the optimal flotation structures independently of the magnitude of the copper price uncertainty. On the other hand, considering that the recovery of mineralogical classes is related directly to the type of flotation equipment, we showed that the recovery influences the optimal structures for flotation systems, contradicting the reports presented in [2,4]. The structures obtained in this work are distinct from those published by Acosta-Flores et al. [8]. Both cases can be attributed to the range of uncertainty used to describe recoveries for flotation equipment, which is based on the design characteristics described above.

From the industrial point of view, the proposed methodology can be applied in different situations. In the early stage of design, the methodology would be useful to identify alternatives for their evaluation and comparison with other industrial designs. In the design stage, it can be integrated with the approach implemented by the designer. In the operation stage, the methodology can be applied to search for improvements in industrial systems by evaluating configuration alternatives that include the selection/inclusion of flotation and grinding equipment. Furthermore, it could be integrated with the mine planning model by incorporating the uncertainty in fed mineralogical species. For example, geometallurgy aspects could be included in planning, relating these issues with a plant's retrofitting.

\section{Conclusions}

In this work, a methodology based on mathematical programming and uncertainty analysis was proposed to address the effect of structures, the selection of equipment, and metal price on the operability of flotation systems. The proposed procedure included flotation stages, grinding stages, and metal price modeled via distribution functions and was applied to design structures for flotation systems processing copper ore and operating under uncertainty. The results revealed that the set of optimal structures for flotation systems is small, including structures implementing cell banks, flotation columns, or both, indicating the influence of flotation equipment type on the optimal structures for flotation systems. These structures exhibited favorable conditions to face uncertainty, and 
consequently these structures offer conditions favoring both optimal operation and the maximization of revenues generated by flotation systems. From the research performed, the following conclusions arise:

- Using mathematical programming and uncertainty analysis, we determined structures presenting favorable conditions for facing operational and economic uncertainty and consequently conditions favoring flexibility/resilience to determine an optimal operation region;

- The selection of flotation equipment and metal price influenced the percentages of structures in the optimal set. A higher percentage of optimal solutions of one structure implies a greater capacity to face operational and metal price changes. A high copper price reduced the number of primal optimal structures and promoted the appearance of new structures.

Therefore, the obtained results allow the separation of the design of the flotation systems into two stages: first, a set of optimal structures exhibiting favorable conditions to face uncertainty is determined; second, the optimal operation is established via resilience/flexibility approaches after the previous determination of the equipment design parameters.

Author Contributions: Conceptualization, F.A.L. and L.A.C.; methodology, F.A.L.; software, F.A.L. and R.A.-F.; validation, F.A.L. and R.A.-F.; writing—original draft preparation, F.A.L.; writingreview and editing, F.A.L., R.A.-F., E.D.G. and L.A.C.; funding acquisition, L.A.C. and E.D.G.; project administration, L.A.C. All authors have read and agreed to the published version of the manuscript.

Funding: The authors are grateful for the support of ANID through Anillo, grant No. ACM 170005 and Fondecyt program, grant No. 1180826.

Data Availability Statement: Not applicable.

Acknowledgments: This publication was supported by Agencia Nacional de Investigación y Desarrollo de Chile (ANID), Anillo—grant No. ACM 170005, and Fondecyt program grant number 1180826.

Conflicts of Interest: The authors declare no conflict of interest.

\section{References}

1. Hu, W.; Hadler, K.; Neethling, S.J.; Cilliers, J.J. Determining flotation circuit layout using genetic algorithms with pulp and froth models. Chem. Eng. Sci. 2013, 102, 32-41. [CrossRef]

2. Cisternas, L.A.; Lucay, F.A.; Acosta-Flores, R.; Gálvez, E.D. A quasi-review of conceptual flotation design methods based on computational optimization. Miner. Eng. 2018, 117. [CrossRef]

3. Mendez, D.A.; Gálvez, E.D.; Cisternas, L.A. State of the art in the conceptual design of flotation circuits. Int. J. Miner. Process. 2009, 90, 1-15. [CrossRef]

4. Cisternas, L.A.; Jamett, N.; Gálvez, E.D. Approximate recovery values for each stage are sufficient to select the concentration circuit structures. Miner. Eng. 2015. [CrossRef]

5. Cisternas, L.A.; Acosta-Flores, R.; Lucay, F.; Gálvez, E.D. Mineral Concentration Plants Design Using Rigorous Models. In Computer Aided Chemical Engineering; Zdravko, K., Miloš, B., Eds.; Elsevier: Amsterdam, The Netherlands, 2016; Volume 38, pp. 1461-1466. ISBN 1570-7946.

6. Calisaya, D.A.; López-Valdivieso, A.; de la Cruz, M.H.; Gálvez, E.E.; Cisternas, L.A. A strategy for the identification of optimal flotation circuits. Miner. Eng. 2016. [CrossRef]

7. Acosta-Flores, R.; Lucay, F.A.; Cisternas, L.A.; Gálvez, E.D. Two phases optimization methodology for the design of mineral flotation plants including multi-species, bank or cell models. Miner. Metall. Process. J. 2018, 35, 24-34.

8. Acosta-Flores, R.; Lucay, F.A.; Gálvez, E.D.; Cisternas, L.A. The effect of regrinding on the design of flotation circuits. Miner. Eng. 2020, 156. [CrossRef]

9. Schena, G.D.; Zanin, M.; Chiarandini, A. Procedures for the automatic design of flotation networks. Int. J. Miner. Process. 1997. [CrossRef]

10. Cisternas, L.A.; Méndez, D.A.; Gálvez, E.D.; Jorquera, R.E. A MILP model for design of flotation circuits with bank/column and regrind/no regrind selection. Int. J. Miner. Process. 2006. [CrossRef]

11. Méndez, D.A.; Gálvez, E.D.; Cisternas, L.A. A model of grinding-classification circuit. In Computer Aided Chemical Engineering; Elsevier: Amsterdam, The Netherlands, 2007; Volume 24, pp. 491-496. ISBN 9780444531575.

12. Sahinidis, N.V. Optimization under uncertainty: State-of-the-art and opportunities. Comput. Chem. Eng. 2004, 28, 971-983. [CrossRef] 
13. Montenegro, M.R.; Sepúlveda, F.D.; Gálvez, E.D.; Cisternas, L.A. Methodology for process analysis and design with multiple objectives under uncertainty: Application to flotation circuits. Int. J. Miner. Process. 2013, 118, 15-27. [CrossRef]

14. Jamett, N.; Cisternas, L.A.; Vielma, J.P. Solution strategies to the stochastic design of mineral flotation plants. Chem. Eng. Sci. 2015. [CrossRef]

15. Liang, Y.; He, D.; Su, X.; Wang, F. Fuzzy distributional robust optimization for flotation circuit configurations based on uncertainty theories. Miner. Eng. 2020, 156. [CrossRef]

16. Cisternas, L.A.; Lucay, F.; Gálvez, E.D. Effect of the objective function in the design of concentration plants. Miner. Eng. 2014, 63, 16-24. [CrossRef]

17. Grossmann, I.E.; Calfa, B.A.; Garcia-Herreros, P. Evolution of concepts and models for quantifying resiliency and flexibility of chemical processes. Comput. Chem. Eng. 2014. [CrossRef]

18. Bansal, V.; Perkins, J.D.; Pistikopoulos, E.N. Flexibility analysis and design of dynamic processes with stochastic parameters. Comput. Chem. Eng. 1998. [CrossRef]

19. Mehrotra, S.P.; Kapur, P.C. Optimal-Suboptimal Synthesis and Design of Flotation Circuits. Sep. Sci. 1974. [CrossRef]

20. Reuter, M.A.; van Deventer, J.S.J.; Green, J.C.A.; Sinclair, M. Optimal design of mineral separation circuits by use of linear programming. Chem. Eng. Sci. 1988. [CrossRef]

21. Reuter, M.A.; Van Deventer, J.S.J. The use of linear programming in the optimal design of flotation circuits incorporating regrind mills. Int. J. Miner. Process. 1990. [CrossRef]

22. Schena, G.; Villeneuve, J.; Noël, Y. A method for a financially efficient design of cell-based flotation circuits. Int. J. Miner. Process. 1996. [CrossRef]

23. Guria, C.; Verma, M.; Mehrotra, S.P.; Gupta, S.K. Multi-objective optimal synthesis and design of froth flotation circuits for mineral processing, using the jumping gene adaptation of genetic algorithm. Ind. Eng. Chem. Res. 2005, 44, 2621-2633. [CrossRef]

24. Guria, C.; Verma, M.; Gupta, S.K.; Mehrotra, S.P. Simultaneous optimization of the performance of flotation circuits and their simplification using the jumping gene adaptations of genetic algorithm. Int. J. Miner. Process. 2005, 77, 165-185. [CrossRef]

25. Mendez, D.A.; Galvez, E.D.; Cisternas, L.A. Modeling of grinding and classification circuits as applied to the design of flotation processes. Comput. Chem. Eng. 2009, 33, 97-111. [CrossRef]

26. Ghobadi, P.; Yahyaei, M.; Banisi, S. Optimization of the performance of flotation circuits using a genetic algorithm oriented by process-based rules. Int. J. Miner. Process. 2011, 98, 174-181. [CrossRef]

27. Maldonado, M.; Araya, R.; Finch, J. Optimizing flotation bank performance by recovery profiling. Miner. Eng. 2011. [CrossRef]

28. Lucay, F.A.; Gálvez, E.D.; Cisternas, L.A. Design of flotation circuits using tabu-search algorithms: Multispecies, equipment design, and profitability parameters. Minerals 2019, 9, 181. [CrossRef]

29. Helton, J.C.; Burmaster, D.E. Treatment of aleatory and epistemic uncertainty in performance assesments for complex systems. Reliab. Eng. Syst. Saf. 1996, 54, 91-94. [CrossRef]

30. Helton, J.C.; Oberkampf, W.L. Alternative representations of epistemic uncertainty. Reliab. Eng. Syst. Saf. 2004, 85, 1-10. [CrossRef]

31. Oberkampf, W. Uncertainty quantification using evidence theory. In Proceedings of the Advanced Simulation Computing Workshop, Albuquerque, MN, USA, 22-23 August 2005.

32. Cisternas, L.A.; Swaney, R.E. Separation System Synthesis for Fractional Crystallization from Solution Using a Network Flow Model. Ind. Eng. Chem. Res. 1998, 5885, 2761-2769. [CrossRef]

33. Gálvez, E.D.; Cruz, R.; Robles, P.A.; Cisternas, L.A. Optimization of dewatering systems for mineral processing. Miner. Eng. 2014, 63, 110-117. [CrossRef]

34. Trujillo, J.Y.; Cisternas, L.A.; Gálvez, E.D.; Mellado, M.E. Optimal design and planning of heap leaching process. Application to copper oxide leaching. Chem. Eng. Res. Des. 2014, 92, 308-317. [CrossRef]

35. Puchinger, J.; Raidl, G.R. Combining Metaheuristics and Exact Algorithms in Combinatorial Optimization: A Survey and Classification. In Proceedings of the International Work-Conference on the Interplay between Natural and Artificial Computation; Springer: Berlin/Heidelberg, Germany, 2005; pp. 41-53.

36. InfoMine Copper Price. Available online: http:/ / www.infomine.com/ChartsAndData/ChartBuilder.aspx?z=f\&gf=110563.USD. $1 b \& d r=5 y \& c d=1$ (accessed on 15 February 2021).

37. Raman, R.; Grossmann, I.E. Modelling and computational techniques for logic based integer programming. Comput. Chem. Eng. 1994, 18, 563-578. [CrossRef]

38. Kohmuench, J.N.; Mankosa, M.J.; Thanasekaran, H.; Hobert, A. Improving coarse particle flotation using the HydroFloat ${ }^{\mathrm{TM}}$ (raising the trunk of the elephant curve). Miner. Eng. 2018, 121, 137-145. [CrossRef] 